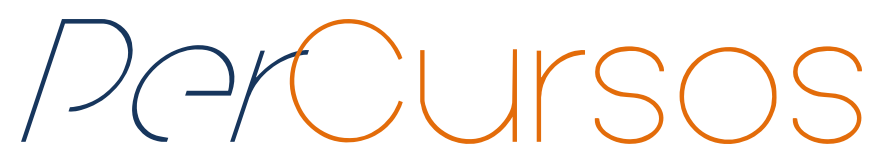

\title{
O Brasil na geografia da TV pública: uma revisão crítico- comparativa
}

\begin{abstract}
Resumo
O surgimento das primeiras emissoras públicas do mundo, implantadas na Europa, coincide com a própria gênese da televisão. Todavia, que forma de organização, gestão e financiamento de TV pública desenvolveu-se, particularmente, no Brasil? Com base nessa problematização, este artigo exploratório percorre matrizes europeias, norte-americanas e latinoamericanas, buscando evidenciar as características elementares do modelo de cada região, comparando-as às características brasileiras mais proeminentes. Notadamente, o serviço público de televisão no Brasil e na América Latina, de um modo geral, encontra maiores dificuldades de afirmação e de cumprimento de sua missão, tanto pela dissensão conceitual entre público e privado quanto pelo baixo padrão de qualidade e audiência, bem como pela falta de autonomia financeira e editorial das emissoras.
\end{abstract}

Palavras-chave: Serviço público de televisão. Europa. América do Norte. América Latina. Brasil.

\section{Lauro Almeida de Moraes}

Doutorando em Geografia na Universidade Federal do Paraná -

UFPR. Editor da Revista

Geografar- ISSN 1981-089X.

Brasil

lauromoraes@ufpr.br

\section{Fernanda Vasques Ferreira}

Doutora em Comunicação pela Universidade de Brasília - UnB. Professora da Univ. Federal do

Oeste da Bahia - UFOB.

Brasil

fernanda.jornalista82@gmail.com

\section{Rafiza Varão}

Doutora em Comunicação pela Universidade de Brasília - UnB. Professora da Universidade de Brasília - UnB.

Brasil

rafiza@gmail.com

\section{Para citar este artigo:}

MORAES, Lauro Almeida de; FERREIRA, Fernanda Vasques; VARÃO, Rafiza. O Brasil na geografia da TV pública: uma revisão crítico-comparativa. Revista PerCursos, Florianópolis, v. 20, n.43, p. 343 - 363, maio/ago. 2019.

\section{DOI: $10.5965 / 1984724620432019343$}

http://dx.doi.org/10.5965/1984724620432019343 


\title{
Brazil in the geography of public TV: a critical- comparative review
}

\begin{abstract}
The emergence of the world's first public broadcasters, established in Europe, coincides with the genesis of television. However, which form of organization, management and financing of public TV was developed particularly in Brazil? Based on this problematization, this exploratory article is carried out covering the European, North American and Latin American matrices, aiming to highlight the elementary characteristics of the model of each region, comparing them to the most prominent Brazilian characteristics. The public television service in Brazil and Latin America, in general, finds significant difficulties affirming and fulfilling its mission, evidenced by the conceptual dissension between public and private, the low quality standards and audience and the lack of station's financial and editorial autonomy.
\end{abstract}

Keywords: Public television service. Europe. North America. Latin America. Brazil. 


\section{Introdução}

A palavra "público" tem sua origem no latim publicus (que significa "relativo ao povo"). O termo latino, por sua vez, vem de populicus, “que pertence ao povo". Essa palavra originou o termo "publicar", ação vinculada especialmente aos meios de comunicação de caráter social, e que designa o ato de tornar comum o conhecimento de determinado fato ou conteúdo, levando-o a ser partilhado por toda uma população ou boa parte dela.

A TV pública, de muitas formas, incorpora essas expressões ao se pretender como uma prestadora de serviços a uma população ou sociedade, compartilhando uma programação de interesse público. No Brasil, a comunicação pública emergiu como uma das modalidades complementares do serviço de radiodifusão na Constituição Federal de 1988, no artigo 223 (BRASIL, 1988). Cabe, no entanto, reconhecer formas de organização, gestão e financiamento de TV pública que se desenvolveram aqui, cotejando-as a outros modelos, a fim de apreender seu comprometimento com a res publica e a população, assim como as relações com as instituições e o mercado.

Com base nessa problematização, este artigo de revisão percorre matrizes europeias, norte-americanas e latino-americanas de serviço público de televisão. A partir de uma pesquisa exploratória, fundamentada em bases nacionais e ibero-americanas, tem como proposta evidenciar as características elementares de cada modelo, comparando-os, especialmente, às características mais proeminentes da TV pública brasileira. Dessa forma, possibilita-se uma aproximação das tensões, dificuldades, possibilidades e características peculiares existentes, particularmente considerando a concepção de comunicação pública, o padrão de qualidade e audiência, bem como a autonomia financeira e editorial das emissoras.

\section{Serviço público de televisão: matrizes}

O surgimento das primeiras emissoras públicas do mundo, implantadas na Europa, coincide com a própria gênese da televisão. Nos dois principais países ibéricos, foram as 
únicas estações existentes durante muitos anos. Só mais tarde, a Rádio e Televisão de Portugal (RTP) e a Televisión Española (TVE) passaram a dividir o espectro televisivo com emissoras comerciais e privadas (LIMA; GONÇALVES, 2011; MACHADO; VÉLEZ, 2012; ROCHA, 2006; SOBRAL, 2012). A outorga de canais para pessoas e empresas privadas só foi autorizada em boa parte dos países europeus a partir da década de 1980. Até então, as emissoras públicas detiveram o monopólio da radiodifusão (BARROS FILHO, 2011).

\section{TV pública na Europa}

O modelo de TV pública mais conhecido e referenciado no mundo é o da British Broadcasting Corporation (BBC), cujas primeiras emissões regulares ocorreram na década de 1930. Seu serviço é pago pelos cidadãos ingleses por meio de uma taxa anual de contribuição. Nos últimos anos, tal cobrança tem enfrentado resistência e questionamentos frequentes (FREIRE, 2013). De qualquer modo, trata-se de um sistema que garantiu autonomia, independência editorial e uma TV com níveis elevados de audiência e alto padrão de qualidade, cujo reconhecimento no Brasil ficou marcado pela obra A melhor TV do mundo: o modelo britânico de televisão (LEAL FILHO, 1997). Um conselho composto por 12 pessoas representativas da sociedade, sem vínculos com organizações e emissoras comerciais, é o responsável pela nomeação da direção executiva da BBC. Os conselheiros são indicados pelo primeiro-ministro e, formalmente, nomeados pela rainha (VALENTE, 2009d).

O padrão britânico inspirou a organização da radiodifusão na então Alemanha Ocidental, especialmente no que tange aos princípios e missão do serviço público. Já em relação à distribuição descentralizada e federativa, toma como base o sistema norteamericano (BARROS FILHO, 2011). Dessa forma, a Arbeitsgemeinschaft der Rundfunkanstalten Deutschlands (ARD) e a Zweites Deutsches Fernsehen (ZDF) integram uma rede, composta por 16 emissoras públicas espalhadas por 12 estados, em que $75 \%$ da receita advém de verbas federais. Dois conselhos, formados por membros indicados por partidos, organizações diversas e governos regionais e federal, dirigem esse sistema. 
Apenas o conselho de Radiodifusão da ZDF é formado por 77 conselheiros (FUNDACIÓN KONRAD ADENAUER, 2009; VALENTE, 2009a).

A matriz da comunicação pública francesa é bastante dependente e atrelada ao Estado (OTONDO, 2008). No complexo sistema da France Télévisions, o Conselho de Administração é o órgão responsável pela gestão. Com mandato de cinco anos, compõese de 14 membros: quatro parlamentares, cinco do Estado e cinco do Conselho Superior do Audiovisual, formado pela Presidência da República, Assembleia Nacional e Senado. Os diretores gerais das quatro emissoras da France Télévisions são nomeados, então, pelo presidente do Conselho de Administração (VALENTE, 2009C). Em 2011, a publicidade foi totalmente eliminada da televisão pública francesa. Sendo assim, verbas orçamentárias cobrem a maior parte dos custos (LOPES, 2015).

Com relativo atraso temporal em relação à Inglaterra, França e Alemanha, a televisão pública disseminou-se pela Europa ao longo da década de 1950, chegando - por ordem das primeiras emissões - aos Países Baixos, Itália, Bélgica, Dinamarca, Áustria, Luxemburgo, Suécia, Espanha, Portugal, Suíça, Finlândia e Noruega (BARROS FILHO, 2011). Tal incremento também ocorre no Leste europeu, todavia sob forte controle dos governos socialistas e da política da então URSS.

As TVs públicas pioneiras na Europa originaram-se, portanto, sob a tutela do Estado, porém o controle social avança junto ao fortalecimento da cidadania e dos valores democráticos. Desse modo, a criação de conselhos representativos e a participação pública na gestão ampliaram-se gradativamente no período pós-guerra. Além da presença de conselhos de representantes - uns mais outros menos atuantes são propriedades comuns a grande parte dessas emissoras, o modelo público de gestão e o financiamento misto: fundamentalmente estatal e suplementado por receitas próprias (CAMPOS-FREIRE, 2012). Embora com prestígio menor do que outrora - seja pela má gestão em algumas emissoras, cortes de investimentos, sobretudo após a crise econômica europeia iniciada em 2007, e questionamentos acerca da eficiência e necessidade ou da contribuição dos cidadãos para mantê-las, como ocorre em relação à BBC - "até hoje as redes públicas têm forte presença nos países europeus" (BUCCl, 2010, p. 8). 
Como salienta Bucci (2010), a radiodifusão na Europa surge com uma utopia da comunicação pública, balizada em uma forte noção de proteção da esfera pública - em sua acepção habermasiana - tanto dos interesses comerciais quanto governamentais. Modelo que sucumbe a partir da privatização dos primeiros canais.

Pelo menos até meados da década de 1980, a fatia mais importante da radiodifusão nesses países ainda era controlada pelas instituições públicas. Mais tarde, alguns canais foram privatizados e, estabeleceu-se a partir de então um novo equilíbrio entre emissoras públicas e comerciais. Até hoje, as primeiras ocupam lugar de destaque e, não raro, de liderança, nos rankings de audiência. Mas, de qualquer maneira, a mentalidade nesses países sofreu um deslocamento, incorporando a ideia de que a comunicação comercial também não poderia faltar na ordem democrática; a convivência entre os sistemas público e comercial seria bem mais saudável do que o monopólio do primeiro. (BUCCl, 2010, p. 8)

Na América do Norte, embora a base da matriz de radiodifusão seja privada e comercial, regras e regulações estatais possibilitaram modelos bem-sucedidos na comunicação pública. Sendo assim, os sistemas norte-americano e canadense também merecem destaque no cenário mundial das televisões públicas.

\section{TV pública na América do Norte}

O modelo de financiamento da Canadian Broadcasting Corporation (CBC) inclui receitas a partir de contribuição dos cidadãos, por meio da assinatura de serviços específicos. Todavia, o fundo governamental canadense compõe a maior parcela da receita (SILVA, 2009a). Outras fontes são a publicidade e verbas que Fraga classifica de heterodoxas, como "venda de programas, aluguel de instalações e de prédios de sua propriedade, taxas de estacionamento e licenciamento de produtos" (2013, p. 23). Todas as atividades da corporação ficam sob o comando de um Conselho Curador, composto por 12 integrantes. Os integrantes desse conselho, que não podem ter ligação com a área de radiodifusão, são indicados pelo Governador-Geral (SILVA, 2009a, p. 89-91). 
A Public Broadcasting Service (PBS) dos EUA, por sua vez, é de fato uma federação americana de emissoras públicas e independentes, com 355 emissoras associadas. A maioria operada por organizações comunitárias e faculdades/universidades e, em menor escala, órgãos vinculados a governos estaduais e municipais. O sinal transmitido nacionalmente pela PBS chega a cada uma das estações, que também veiculam conteúdo voltado para a comunidade local (OTONDO, 2008). A exemplo de grande parte das emissoras europeias, o financiamento é garantido pelo aporte de recursos públicos, mormente federais e estaduais. Contudo, há um considerável fatiamento das fontes, que também incluem doações de fundações civis, cidadãos e empresas privadas, além de comercialização de conteúdo entre membros da rede ou com emissoras de outros países (SILVA, 2009b). O Conselho Diretor é formado por 27 representantes. Um destes conselheiros preside a direção executiva da corporação, que conta com 12 membros. Conforme destaca Otondo (2008, p. 270), a TV pública norte-americana “é pública pelo seu caráter social e educativo e por não ter finalidade lucrativa", mas a regulação da atividade dá-se de acordo com as leis de mercado, da concorrência e da liberdade individual, ou seja, sob os princípios da iniciativa privada.

\section{TV Pública na América Latina}

O cenário da radiodifusão pública é bem mais complexo na América Latina, onde a conjuntura política foi determinante para o padrão adotado na maioria dos países. A TV chegou ao continente nas décadas de 1950 e 1960, quando regimes autoritários assolavam a maioria dos países, o que resultou na predominância de um "modelo de televisão do governo", conforme define Barros Filho (2011, p. 34) - com exceção do Uruguai, Brasil e México, onde se desenvolveram matrizes vinculadas ao padrão comercial e privado norte-americano. Como herança, segundo o autor, ainda existem emissoras chamadas públicas "apenas pelo fato de pertencerem ao Estado ou a alguma comunidade, ou, mesmo, em decorrência de dependerem de subvenções dos governos" (BARROS FILHO, 2011, p. 34). 
O estágio incipiente da televisão pública latino-americana é corroborado pelos recentes estudos do Observatório da Radiodifusão Pública na América Latina. Um balanço apresentado por Del Bianco, Esch e Moreira (2013) aponta que, mesmo tendo adentrado os regimes democráticos, as emissoras públicas do continente conservaram, em grande parcela, o discurso atrelado à agenda governamental e uma estrutura administrativa centralizada. Desse modo, a mídia comercial assumiu o protagonismo na maioria dos países. Passaram a atrair as maiores audiências e verbas publicitárias - públicas e privadas - e tornaram-se influentes e concentradas sob o domínio de poucos grupos. De outro lado, no campo das televisões públicas, "com o tempo, a maioria ficou estigmatizada como sinônimo de programação de baixa qualidade técnica, sem atrativos e oficialista" (DEL BIANCO et al., 2013, p. 65). Como sequela, instalou-se a crise estrutural aludida por Fuenzalida (2015), em cuja base o autor também identifica a falta de uma programação capaz de reter audiência, além da má administração industrial-empresarial e da não sustentação econômica das emissoras.

O que se percebe na América Latina, portanto, é uma tentativa de estabeleceremse novos marcos conceituais para a transformação dos modelos existentes até então, a fim de conformar uma radiodifusão efetivamente pública. Nesse sentido, o exemplo mais emblemático no continente, atualmente, é o do Chile, onde houve "uma mudança radical no modelo de televisão pública usual na América Latina, baseada em três pontos: ruptura com o modelo estatal [...], independência financeira do governo [...] e representação democrática na gestão e programação" (OTONDO, 2008, p. 78). Essa situação remete às reformas, iniciadas na década de 1990, na Televisión Nacional de Chile (TVN), a partir da qual cabe relacionar outras experiências latino-americanas.

Uma das primeiras questões tratadas no caso chileno diz respeito à natureza jurídica da emissora. Como apresenta Fuenzalida (2015), criou-se uma empresa estatal autônoma. Essa companhia possui patrimônio próprio e é encarregada de administrar e autofinanciar a TVN. Nessa linha de ação de reordenamento jurídico, empresas públicas destinadas a gerir as emissoras estatais também foram criadas, nos últimos anos, no Equador (Empresa Pública Televisión y Radio de Ecuador E.P. - RTVEcuador), Bolívia (Bolívia TV), Argentina (Radio y Televisión Argentina Sociedad del Estado - RTA S.E.) e 
Brasil (Empresa Brasil de Comunicação - EBC) (DEL BIANCO et al., 2013). Sobre o advento da $E B C$, é pertinente a colocação de Valente (2009b, p. 269): “a criação da EBC e de seu serviço televisivo, a TV Brasil, significou uma tentativa de superação do passado de atrelamento dos canais públicos aos governos e autoridades para a apontar a direção da construção de iniciativas efetivamente públicas". A despeito de almejar a independência, tanto o corpo dirigente da EBC quanto das empresas públicas dos demais países citados são nomeados por autoridades do governo federal.

Vale lembrar que até mesmo "a mais exitosa experiência de TV pública já realizada no Brasil" (LEAL FILHO, 2009, p. 324), a TV Cultura, tem a sua história marcada por interferências de cunho político-eleitoral, algumas com a manifesta finalidade de torná-la canal de expansão das realizações do governo paulista (CUNHA LIMA, 2009). Daí a importância de mecanismos de participação social, tanto internos - como as ouvidorias instituídas nas emissoras de TV da Colômbia e pelos conselhos de Administração e Curador da EBC, no Brasil - quanto externos - a exemplo do Consejo Consultivo Honorario de los Medios Públicos, na Argentina; Consejo Consultivo de Rádio Televisión de Perú (CONCORTV), no Peru; e Consejo Nacional de Televisión (CNTV), no Chile. A despeito de representarem um avanço, em muitas das agências reguladoras e conselhos consultivos e deliberativos ainda é aguda a presença governamental (DEL BIANCO et al., 2013).

Outro ponto fundamental, tanto no que tange à independência editorial quanto à sustentação das televisões públicas na América Latina, são as fontes de financiamento. A taxação e o aumento de impostos, geralmente, provocam agudos focos de resistência às tentativas de angariar receita a partir da contribuição dos cidadãos. O modelo chileno decidiu, então, pelo "autofinanciamiento substantivamente publicitário" (FUENZALIDA, 2009, p. 13), disputando recursos no mercado. Uma forma de financiamento cada vez mais aceita na América Latina, que, a despeito de conferir maior autonomia à gestão em relação ao governo, também levanta questionamentos acerca da emergência de uma “dupla ou a múltipla dependência” (LOPES, 2015, p. 45).

Na maioria dos casos, no entanto, os recursos advindos da publicidade não são suficientes para manter as emissoras. Tal discussão existe no próprio Chile. Segundo Fuenzalida: 
o financiamento exclusivamente publicitário, no caso da TVN do Chile, introduziu limitações na programação, pois há programas que não são interessantes para a publicidade; a carência de recursos públicos não tem facilitado a regionalização desse canal. São necessários, portanto, recursos públicos (FUENZALIDA, 2009, p. 13, tradução nossa).

Como alternativa a circunstâncias desse porte, além da publicidade, patrocínios, apoios culturais, prestação de serviços, licenciamento de produtos e/ou venda de anúncios comerciais - de acordo com o que permite a legislação de cada nação - alguns países também têm constituído fundos específicos voltados para as emissoras públicas. Na Argentina, decidiu-se reverter $20 \%$ dos impostos estabelecidos pela Ley de Servicios de Comunicación Audiovisual para financiar a RTA S.E. Colômbia e Venezuela criaram, por sua vez, Fondo para el Desarrollo da la Televisión y Contenidos e Fondo de Responsabilidad Social, respectivamente, para financiar o sistema público de comunicação (DEL BIANCO et al., 2013, p. 67-68). No Brasil, a Contribuição para o Fomento da Radiocomunicação Pública, criada em 2008, foi barrada na justiça. Uma ação interposta por empresas de telecomunicação do país questiona a constitucionalidade do subsídio e os recursos, depositados em juízo, encontram-se retidos na Justiça (LOPES, 2015).

Notadamente, as pesquisas e o debate público apontam que tanto a discussão quanto a legislação na América Latina enfrentam entraves peculiares a países em que a tradição de comunicação pública é curta, senão inexistente na prática. Particularmente no Brasil, observa-se o confinamento das emissoras universitárias e comunitárias no sinal a cabo. As emissoras educativas estaduais, por sua vez, "articulam-se para assumir papel mais central do que o de simples integrantes da rede encabeçada pela TV Brasil" (VALENTE, 2009b, p. 289). Avanço mais significativo ocorre no campo das TVs legislativas e judiciárias. A despeito de deslocadas do conceito estrito de TV pública, estas ganham notoriedade a cada acontecimento político de grande relevância no país e revelam-se “importantes instrumentos de cidadania, possibilitando o acompanhamento mais transparente do cotidiano do parlamento" (TORRES, 2009, p. 35). Pela TV Câmara e TV Senado, o Brasil acompanhou o processo de impeachment da presidente Dilma Rousseff. 


\section{TV pública no Brasil}

O caso brasileiro de implantação da TV, como meio eletrônico, está intrinsecamente associado ao poder político e privado. A TV, portanto, é legado de um país em que a censura, o autoritarismo e a concentração do poder econômico vigoram ou vigoraram em diversos períodos. Diferentemente do rádio - um projeto de RoquettePinto com bases na educação e, portanto, com finalidade pública e não comercial - a TV surge da iniciativa, do desejo e da vaidade de Assis Chateaubriand de se aventurar em mais um de seus empreendimentos no ramo da comunicação, com a fundação da TV Tupi, em 1950. À deriva, a regulamentação da televisão no Brasil sempre esteve nas mãos daqueles que entenderam a TV como um meio de comunicação a serviço de um projeto político, conforme aponta Herz (1987).

Não obstante, as TVs públicas brasileiras seguiram, segundo Valente (2009e), a condição de "complementaridade marginal”. De largada, a TV pública sofre interferência e sua implantação é assediada por grupos políticos e econômicos. Roquette Pinto, Fernando Tude de Souza, o engenheiro José de Oliveira Reis e o general Lauro de Medeiros estariam, nos anos 1950, responsáveis pela implantação de uma TV pública no Brasil, a partir do Decreto Presidencial de $\mathrm{n}^{\circ}$ 30.832, de 10 de maio de 1952, que concedia “outorga à Prefeitura do Distrito Federal para explorar um canal de televisão por meio da Rádio Emissora Roquette-Pinto, nome à época da Rádio MEC" (VALENTE, 2009e, p. 54). A expectativa era implantar uma TV educativa que, a partir do decreto, já tinha contrato assinado com empresa estadunidense para aquisição de equipamentos e montagem de estação. Estranhamente, o então prefeito do Distrito Federal, José Carlos Vital, foi exonerado e substituído pelo coronel Dulcídio Cardoso e após a exoneração, o projeto de implantação de uma TV pública no Distrito Federal foi “engavetado”. Federico (1982), apud Valente (2009e, p. 55), afirma "que o Governo teria sido pressionado por grupos políticos e econômicos, mormente por Assis Chateaubriand, que via na força de comunicação da Nacional uma ameaça a seu império". 
Ao citar o discurso ${ }^{1}$ de Chateaubriand na ocasião de implantação da TV Tupi, Leal Filho (2000) afirma que a referência histórica da implantação da TV no Brasil demonstra, com clareza, que o modelo brasileiro de radiodifusão se trata de uma articulação “perfeita” entre o privado e o público, refletindo no conteúdo. "A ideia de uma programação de nível elevado sucumbe diante dos interesses comerciais, não apenas nas suas relações essencialmente econômicas, mas, como se vê no exemplo da Nacional, também no âmbito político" (LEAL FILHO, 2000, p. 157). É nesse contexto institucional que a televisão surge no Brasil: baseada em um só modelo, o comercial, conforme também destaca Carrato (2005). E é nos anos 1960 que a TV se consolida como o mais importante instrumento da indústria cultural no Brasil (BRITTOS, 1999). Quase duas décadas depois é que surge uma alternativa às emissoras comerciais: a implantação da Rádio e TV Cultura de São Paulo, da Fundação Padre Anchieta, que buscou aproximar-se do modelo britânico, ao se inspirar no Conselho de Governadores da BBC de Londres, e adotou o Conselho Curador, composto por representantes de instituições públicas e privadas de São Paulo.

Apesar de seguir o modelo institucional da BBC, do ponto de vista da gestão financeira, a Rádio e TV Cultura de São Paulo nunca teve independência financeira e se manteve dependente dos recursos do governo estadual. Isso significa que durante o governo militar, os recursos da emissora eram oriundos da veiculação de propaganda oficial e de conteúdos obrigatórios. Leal Filho (2000) salienta que, somente após a metade dos anos 1990, é que o governo estadual tentou 'reduzir os gastos' e cogitou manter a Fundação Padre Anchieta a partir de taxa adicional nas contas de energia elétrica. "Foi a primeira vez que surgiu uma proposta concreta para retirar a televisão

\footnotetext{
1 "Esse transmissor foi erguido com a prata da casa, isto é, com os recursos de publicidade que levantamos, sobre as Pratas Wolff e outras menos maciças pratas da casa; a Sul América que é o que pode haver de bem brasileiro, as lãs Sams, do Moinho Santista, arrancadas ao coiro das ovelhas do Rio Grande, e mais do que tudo isso, o guaraná Champagne da Antarctica, que é a bebida dos nossos selvagens. O cauim dos bugres do pantanal mato-grossense e de trechos do vale amazônico. Atentai e verei mais fácil do que se pensa alcançar uma televisão: com Prata Wolff, lãs Sams bem quentinhas, Guaraná Champagne borbulhante de bugre e tudo isso amarrado e seguro no Sul América, faz-se um bouquet de aço e pendura-se no alto da torre do Banco do Estado, um sinal da mais subversiva máquina de influenciar a opinião pública - uma máquina que dará asas à fantasia mais caprichosa e poderá juntar os grupos humanos mais afastados" (ORTIZ, 1998 apud LEAL FILHO, 2000, p. 154).
} 
pública paulista da dependência do Tesouro estadual. Recebida com crítica e ceticismo pela imprensa, a proposta não prosperou" (LEAL FILHO, 2000, p. 161).

A outra experiência de implantação de algo próximo de uma TV pública veio com o Decreto-Lei 236, em 1967. Foi criada a Fundação Centro Brasileiro de TV Educativa (FCBTVE) que tinha como objetivo ser um órgão oficial com o intuito de fomentar a programação educativa, segundo Coutinho e Oliveira Filho (2014) e Valente (2009c). A partir de 1967, o Brasil assiste ao nascimento de TVs educativas, criadas pelos Estados, tendo como precursora a TV Universitária de Pernambuco. Em 1975, entrou no ar também a TVE do Rio de Janeiro (Fundação Roquette-Pinto). A emissora transformou-se em uma organização social - a Associação Educativa Roquette-Pinto (Acerp) - e, em 15 de dezembro de 1975, a partir da Lei 6.301, constituiu-se a Empresa Brasileira de Radiodifusão (Radiobrás), vinculada ao Ministério das Comunicações, com os seguintes objetivos:

I - implantar e operar as emissoras, e explorar os serviços de radiodifusão do Governo Federal; II - implantar e operar as suas próprias redes de Repetição e Retransmissão de Radiodifusão, explorando os respectivos serviços; III - realizar difusão de programação educativa, produzida pelo órgão federal próprio, bem como produzir e difundir programação informativa e de recreação; IV - promover e estimular a formação e o treinamento de pessoal especializado, necessário às atividades de radiodifusão; V - prestar serviços especializados no campo de radiodifusão; VII - exercer outras atividades afins, que lhe forem atribuídas pelo Ministério das Comunicações. (BRASIL, 1975, p. 16681)

Como pode-se observar, a gênese da Radiobrás já a define como sendo um aparato do Estado, vinculada ao Ministério das Comunicações, e, conforme explicita Aguiar (2012, p. 134), é um “órgão responsável pela exploração dos serviços de rádio e TV do regime militar". Ou seja, mesmo fora do circuito comercial, a televisão conformou-se como um aparelho de poder e hegemonia (RAMOS, 2005).

Em 1998, foi criada a Associação Brasileira das Emissoras Públicas, Educativas e Culturais (ABEPEC), a partir da organização dos dirigentes da TV Cultura e das TVs educativas existentes no país. Em evento em Salvador, Carrato (2005) explicita o advento 
da ABEPEC como uma tentativa de romper o obstáculo quase impossível de dar voz às emissoras e, enquanto Associação, contribuir para o enfrentamento do segmento no sentido de manter em "sobrevida" as emissoras que se distanciam do modelo comercial.

Das 20 emissoras que integram a ABEPEC, a maioria não possui ordenamento jurídico compatível com sua função, enfrenta problemas trabalhistas sérios, conta com orçamento insuficiente para fazer face a suas atividades e não dispõe de recursos para investir em novos formatos de programas e nem em tecnologia digital. Como, nos campos político, econômico, cultural e social aconteceram avanços significativos no país, a exemplo das eleições diretas em todos os níveis e do fim da censura estatal à imprensa, era de se esperar que progressos também tivessem ocorrido no que diz respeito à mídia, em especial à mídia televisiva voltada para a educação e a cultura, as chamadas TVs públicas que, no Brasil, acabaram sendo acomodadas sob o impreciso e vago rótulo de "emissoras educativas e culturais". A realidade, no entanto, aponta para direção oposta. A situação destas emissoras nunca foi tão dramática. E o mais grave é que a maioria dessas emissoras está agonizando em meio a um boicote difícil de ser percebido e rompido. Boicote que começa pelos próprios governos às quais estão vinculadas, passa pelas TVs comerciais, anunciantes e agências de publicidade e envolve até setores que deveriam ser seus mais fiéis aliados, como os sindicatos e os seus próprios funcionários. (CARRATO, 2005, p. 02)

A partir das discussões e anseios da sociedade civil, explicitados no I Fórum Nacional da Televisão Pública, em 2006, a TV Brasil foi criada em 2007. Segundo o que consta no site da emissora, a TV Brasil é independente e democrática e tem como objetivo ofertar conteúdo e programação informativa, cultural, artística, com vistas a constituir uma cidadania ${ }^{2}$ A TV Brasil é gerida pela Empresa Brasil de Comunicação (EBC). Conforme consta no Manual de Jornalismo da EBC, lançado em 2013, trata-se de uma instituição democrática brasileira: pública, inclusiva e cidadã, compromissada com a responsabilidade social e com a diversidade de opiniões. Segundo esse manual, um dos

\footnotetext{
2 "A TV Brasil veio atender à antiga aspiração da sociedade brasileira por uma televisão pública nacional, independente e democrática. Sua finalidade é complementar e ampliar a oferta de conteúdos, oferecendo uma programação de natureza informativa, cultural, artística, científica e formadora da cidadania. Criada em dezembro de 2007, a TV Brasil é gerida pela Empresa Brasil de Comunicação (EBC), também responsável pela Agência Brasil, Radioagência Nacional, TV Brasil Internacional, Rádios MEC AM e FM, além das Rádios Nacional do Rio de Janeiro, Nacional AM e FM de Brasília, Nacional da Amazônia e Nacional do Alto Solimões" (TV Brasil, 2017).
} 
princípios da emissora é a "Autonomia para definir a produção, programação e veiculação de seus conteúdos” (EMPRESA BRASIL DE COMUNICAÇÃO, 2016, p. 4).

Todavia, em pesquisa realizada pela Universidade Federal de Juiz de Fora (UFJF), analisando o telejornal da TV Brasil, Coutinho e Oliveira Filho (2014) concluem o contrário do manual da EBC: há dependência das agendas oficiais e a cobertura internacional se mostra superficial. Ademais, a emissora evitaria o debate político, até mesmo como estratégia de combater possíveis interferências. No entanto, ao apontar para a dependência de fontes oficiais, o jornalismo da TV Brasil demonstra situações semelhantes ao jornalismo tradicional e comercial: constrangimentos institucionais e o que Wolf (2001) aponta como dificuldade de selecionar e pluralizar as fontes de informação.

\section{Anotações finais}

Notadamente, o serviço público de televisão na América Latina, de um modo geral, encontra maiores dificuldades de afirmação e de cumprimento de sua missão, em contraste com as matrizes europeias e norte-americanas (Quadro 1). Isso fica evidenciado pelo baixo padrão de qualidade e audiência atingidos até então, bem como pela falta de autonomia financeira e editorial das emissoras.

Quadro 1 - Matrizes predominantes de TV pública por região

\begin{tabular}{|c|c|c|c|}
\hline \multirow{2}{*}{ Gestão } & Europa & América do Norte & América Latina \\
\hline & $\begin{array}{c}\text { Modelo público } \\
\text { com conselhos de } \\
\text { representantes }- \\
\text { uns mais outros } \\
\text { menos atuantes. }\end{array}$ & $\begin{array}{c}\text { Pública, com conselho } \\
\text { diretor ou curador, e } \\
\text { regulação da atividade } \\
\text { de acordo com as leis de } \\
\text { mercado, da } \\
\text { concorrência e da } \\
\text { liberdade individual. }\end{array}$ & $\begin{array}{c}\text { Edministrativa } \\
\text { centralizada por } \\
\text { meio de empresas } \\
\text { públicas com corpo } \\
\text { dirigente nomeado } \\
\text { por autoridades } \\
\text { governamentais. }\end{array}$ \\
\hline Financiamento & $\begin{array}{c}\text { Misto: } \\
\text { fundamentalmente } \\
\text { estatal e }\end{array}$ & $\begin{array}{c}\text { Misto com considerável } \\
\text { fatiamento das fontes: } \\
\text { recursos públicos, }\end{array}$ & $\begin{array}{c}\text { Predominantement } \\
\text { e estatal por meio } \\
\text { de fundos }\end{array}$ \\
\hline
\end{tabular}




\begin{tabular}{|c|c|c|c|}
\hline & $\begin{array}{l}\text { suplementado por } \\
\text { receitas próprias. }\end{array}$ & $\begin{array}{l}\text { doações de fundações } \\
\text { civis, cidadãos e } \\
\text { empresas privadas, } \\
\text { publicidade e } \\
\text { comercialização de } \\
\text { conteúdo. }\end{array}$ & $\begin{array}{c}\text { específicos voltados } \\
\text { para as emissoras } \\
\text { públicas. }\end{array}$ \\
\hline Organização & $\begin{array}{l}\text { Tanto sistemas } \\
\text { centralizados } \\
\text { quanto redes com } \\
\text { distribuição } \\
\text { descentralizada e } \\
\text { federativa. }\end{array}$ & $\begin{array}{l}\text { Sistema descentralizado } \\
\text { e federativo, com } \\
\text { emissoras públicas e } \\
\text { independentes, } \\
\text { predominantemente } \\
\text { operadas por } \\
\text { organizações } \\
\text { comunitárias e } \\
\text { faculdades/ } \\
\text { universidades. }\end{array}$ & $\begin{array}{l}\text { Sistemas } \\
\text { centralizados, com } \\
\text { predominância de } \\
\text { um modelo de } \\
\text { televisão oficialista. }\end{array}$ \\
\hline Caráter & $\begin{array}{l}\text { Social e educativo, } \\
\text { sem fins lucrativos, } \\
\text { com moderada } \\
\text { interferência } \\
\text { estatal. }\end{array}$ & $\begin{array}{l}\text { Social e educativo, sem } \\
\text { fins lucrativos, com } \\
\text { interferência do } \\
\text { mercado e da } \\
\text { concorrência. }\end{array}$ & $\begin{array}{l}\text { Social e educativo, } \\
\text { sem fins lucrativos, } \\
\text { com interferências } \\
\text { de cunho político- } \\
\text { eleitoral. }\end{array}$ \\
\hline Autonomia & $\begin{array}{c}\text { Relativa, com } \\
\text { moderada a elevada } \\
\text { independência } \\
\text { editorial. }\end{array}$ & $\begin{array}{l}\text { Relativa, com moderada } \\
\text { independência editorial. }\end{array}$ & $\begin{array}{c}\text { Mínima, com } \\
\text { discurso atrelado à } \\
\text { agenda } \\
\text { governamental. }\end{array}$ \\
\hline $\begin{array}{l}\text { Padrão de } \\
\text { qualidade }\end{array}$ & Médio a elevado. & Médio. & Baixo. \\
\hline
\end{tabular}

Fonte: Elaborado pelos autores, 2018.

Até quando perdurará este cenário? Particularmente no Brasil, passadas quase sete décadas do surgimento da TV no país, dilemas antigos permanecem e ganham novos contornos. A instituição de um serviço público de televisão ainda esbarra em tensionamentos presentes desde o princípio da formação do Brasil conforme ficou consagrado na obra de Holanda (1963). O padrão de TV comercial adotado e as várias tentativas de se instituir um modelo de TV pública - frustrado, em grande medida, mas sem perder de vista a expectativa de que contemple, efetivamente, o caráter público refletem a estrutura patrimonialista, paternalista e personalista do país. Com efeito, a história da televisão brasileira reflete a maneira como o país institucionalizou-se, incluindo todas as contradições características dessa institucionalização: uma sociedade calcada no 
coronelismo, com políticas voltadas a favorecer grupos e setores dominantes da economia e com uma televisão que se converte em veículo estatal ou aparelho privado de hegemonia.

De fato, as experiências de emissoras públicas no Brasil seguem em conflito entre o que está escrito, seu regime jurídico, a constituição de seus departamentos e curadorias e o problema conceitual do que vem a ser um serviço público, em conformidade com o que refletimos noutro trabalho (FERREIRA; MORAES; VARÃO, 2016). Nesse sentido, o serviço indica a existência de uma necessidade da população, e a noção de público implica "um atendimento especial que não pode ser feito por empresas comerciais" (LEAL FILHO, 1997, p. 18). Entretanto, essas duas dimensões ainda não se encontraram na televisão brasileira, culminando em uma série de anacronismos e paradoxos, apontados ao longo deste trabalho.

Com efeito, a privatização do que é público por natureza - o espectro eletromagnético - evidencia a primazia do ideário tecnocapitalista de exploração comercial dos serviços de radiodifusão e os desvios praticados pelos entusiastas da televisão no Brasil - engajados e comprometidos com seus anseios de acumulação de capital e/ou favorecimento de determinados projetos políticos. Não obstante, as TVs públicas seguem com 'sobrevida', na utópica expectativa da autonomia financeira e editorial, freada pela incapacidade histórica de desenvolver as potencialidades natas de uma matriz pública de televisão.

No cerne da dificuldade para constituição de um modelo efetivo de TV pública, no Brasil, reside a dissensão conceitual entre público e privado, bem como o dilema de estabelecer-se um serviço de radiodifusão republicano, em favor da res publica - dos cidadãos e da cidadania - sem os tradicionais contornos oligárquicos que caracterizam os conglomerados de mídia no país. Tais constatações, a despeito das utopias, são fundamentalmente relevantes nestes tempos nebulosos, em que até mesmo as conquistas alcançadas e mínimos avanços obtidos a partir da EBC encontram-se numa penumbra. O horizonte é turvo e as incertezas tornam ainda mais necessário reverberar e ampliar essa discussão. 


\section{Referências bibliográficas}

AGUIAR, Itamar. TV Brasil: algo novo no ar. Florianópolis: Tribo da Ilha, 2012.

BARROS FILHO, Eduardo Armando. Por uma televisão cultural-educativa e pública: a TV Cultura de São Paulo, 1960-1974. São Paulo: Cultura Acadêmica, 2011.

BRASIL. Constituição (1988). Constituição da República Federativa do Brasil. Brasília: Senado Federal, 1988.

BRASIL. Lei n. 6.301, de 15 de dezembro de 1975. Institui política de exploração de serviço de radiodifusão de emissoras oficiais, autoriza o Poder Executivo a constituir a Empresa Brasileira de Radiodifusão - RADIOBRÁS, e dá outras providências. Diário Oficial da União, seção 1, Brasília, DF, ano 113, n. 240, p. 16681, 16 dez. 1975.

BRITTOS, Valério Cruz. A televisão no Brasil, hoje: a multiplicidade da oferta. Comunicação \& Sociedade, São Bernardo do Campo, Umesp, n. 31, p. 9-34, 1999.

BUCCI, Eugênio. É possível fazer televisão pública no Brasil? Novos Estudos, São Paulo, CEBRAP, n. 88, p. 5-18, dez. 2010.

CAMPOS-FREIRE, Francisco. Modelos de financiación de las televisiones públicas autonómicas. In: MIGUEL-DE-BUSTOS, Juan Carlos; CASADO-DEL-RíO, Miguel Angel (orgs.). Televisiones autonómicas: evolución y crisis del modelo público d e proximidade. Barcelona: Gedisa, 2012. p. 143-172.

CARRATO, Angela. A TV pública e seus inimigos. In: ENCONTRO LATINO AMERICANO DE ECONOMIA POLÍTICA DA INFORMAÇÃO, COMUNICAÇÃO E CULTURA, 5, 2005, Salvador. Anais [...], Salvador: UFBA, 2005, p. 1-17.

COUTINHO, Iluska; OLIVEIRA FILHO, José Tarcísio da Silva. A TV pública no Brasil: a evolução histórica do formato e o papel da TV Brasil na promoção do jornalismo cidadão. In: ENCONTRO REGIONAL SUDESTE DE HISTÓRIA DA MÍDIA (ALCAR), 3., 2014. Rio de Janeiro. Anais [...] Rio de Janeiro: UFRJ, 2014. p. 1-13.

CUNHA LIMA, Jorge. Uma história da TV Cultura. São Paulo: Imesp, 2009.

DEL BIANCO, Nelia R.; ESCH, Carlos Eduardo; MOREIRA, Sonia Virgínia. Observatório da radiodifusão pública na América Latina: balanço de um ano de atuação. Revista Eptic, São Cristóvão: UFS, v. 15, n. 2, p. 58-73, 2013. 
EMPRESA BRASIL DE COMUNICAÇÃO. Norma de Jornalismo - NOR 801. Brasília: EBC, 2016.

FERREIRA, Fernanda Vasques; MORAES, Lauro Almeida de; VARÃO, Rafiza. Origens da TV pública: um panorama histórico e conceitual. In: SANTOS, Nádia Maria Weber; MORAES, Ana Luiza Coiro. TVs públicas: memórias de arquivos audiovisuais. São Leopoldo: Oikos, 2016, p. 82-96.

FRAGA, Marcus Vinícius. Lições do Canadá. Revista do Conselho Curador da EBC, Brasília: EBC, n. 2, p. 22-23, dez. 2013.

FREIRE, Emma Elliott. Britain's BBC tax: clogging the courts and slanting the news.

Foundation For Economic Education. [Atlanta], 2013. Disponível em:

https://fee.org/articles/britains-bbc-tax/. Acesso em: 11 set. 2013.

FUENZALIDA, Valerio. Nuevas tendencias de la televisión pública en América Latina. In: FUNDACIÓN KONRAD ADENAUER. Televisión pública: experiencias de Alemania y Latinoamérica. Buenos Aires: Konrad Adenauer Stiftung, 2009. p. 11-30.

FUENZALIDA, Valerio. Situación de la televisión pública en América Latina. Diálogos de la Comunicación, Medellín, n. 74, 2015, p. 1-21.

FUNDACIÓN KONRAD ADENAUER. Televisión pública: experiencias de Alemania y Latinoamérica. Buenos Aires: Konrad Adenauer Stiftung, 2009.

HERZ, Daniel. A história secreta da Rede Globo. Porto Alegre: Tchê, 1987.

HOLANDA, Sérgio Buarque de. Raízes do Brasil. Brasília: UnB, 1963.

LEAL FILHO, Laurindo. A melhor TV do mundo: o modelo britânico de televisão. São Paulo: Summus, 1997.

LEAL FILHO, Laurindo. TV Pública. In: HAMBURGER, Esther; BUCCI, Eugênio. (orgs.). A TV aos 50: criticando a televisão brasileira no seu cinqüentenário. Fundação Perseu Abramo, São Paulo, 2000. p. 153-165.

LEAL FILHO, Laurindo. Percalços da TV pública: o caso da TV Cultura. Estudos Avançados, São Paulo: USP, v. 23, n. 67, p. 323-327, 2009.

LIMA, Maria Érica de Oliveira; GONÇALVES, Emille Laís Cândido. O conceito de cidadania aplicado à televisão pública portuguesa: um olhar prático-histórico. Revista Temática, João Pessoa: UFPB, v. 7, n. 5, p. 1-13, 2011. 
LOPES, Ivonete Silva. Televisão pública e modelos de financiamento: análise do caso brasileiro. Revista Eptic, São Cristóvão: UFS, v. 17, n. 1, p. 33-48, 2015.

MACHADO, Arlindo; VÉLEZ, Marta Lucía. Televisão e arte contemporânea. ARS, São Paulo: USP, v. 10, n. 19, p. 24-37, 2012.

OTONDO, Teresa Montero. Televisão pública na América Latina: para quê e para quem? 2008. Tese (Doutorado em Integração da América Latina) - Escola de Comunicação e Artes , Universidade de São Paulo, São Paulo: USP, 2008.

RAMOS, Murilo César. A força de um aparelho privado de hegemonia. Rede Globo: 40 anos de poder e hegemonia. São Paulo: Paulus, 2005.

ROCHA, Liana Vidigal. A televisão pública num ambiente de competição comercial: estudo dos modelos brasileiro e português. 2006. Tese (Doutorado em Ciências da Comunicação) - Escola de Comunicação e Artes, Universidade de São Paulo, São Paulo: USP, 2006.

SILVA, Sivaldo Pereira. Sistema público de comunicação do Canadá. In: INTERVOZES. Sistemas públicos de comunicação no mundo: experiências de doze países e o caso brasileiro. São Paulo: Paulus, Intervozes, 2009a, p. 85-96.

SILVA, Sivaldo Pereira. Sistema público de comunicação dos Estados Unidos. In: INTERVOZES. Sistemas públicos de comunicação no mundo: experiências de doze países e o caso brasileiro. São Paulo: Paulus, Intervozes, 2009b, p. 137-156.

SOBRAL, Filomena Antunes. Televisão em contexto português: uma abordagem histórica e prospetiva. Millenium, Viseu, IPV, v. 17, n, 42, 2012, p. 143-159.

TORRES, Rodrigo Murtinho de Martinez. Televisão pública no Brasil: estudo preliminar sobre suas múltiplas configurações. Contemporânea, Rio de Janeiro, UERJ, v. 7, n. 1, 2009, p. 27-39.

TV BRASIL. Sobre a TV. 2017. Disponível em: http://tvbrasil.ebc.com.br/sobreatv. Acesso em: 05 de junho de 2017.

VALENTE, Jonas. Sistema público de comunicação da Alemanha. In: INTERVOZES.

Sistemas públicos de comunicação no mundo: experiências de doze países e o caso brasileiro. São Paulo: Paulus, Intervozes, 2009a. p. 47-62.

VALENTE, Jonas. Sistema público de comunicação da França. In: INTERVOZES. Sistemas públicos de comunicação no mundo: experiências de doze países e o caso brasileiro. São Paulo: Paulus, Intervozes, 2009b. p. 157-174. 
VALENTE, Jonas. Sistema público de comunicação do Brasil. In: INTERVOZES. Sistemas públicos de comunicação no mundo: experiências de doze países e o caso brasileiro. São Paulo: Paulus, Intervozes, 2009c. p. 269-290.

VALENTE, Jonas. Sistema público de comunicação do Reino Unido. In: INTERVOZES. Sistemas públicos de comunicação no mundo: experiências de doze países e o caso brasileiro. São Paulo: Paulus, Intervozes, 2009d. p. 235-254.

VALENTE, Jonas. A criação da TV Brasil e sua inserção no modo de regulação setorial da televisão brasileira. 2009. Dissertação (Mestrado em Comunicação) - Faculdade de Comunicação, Universidade de Brasília, Brasília , 2009 e.

WOLF, Mauro. Teorias da comunicação. Lisboa: Presença, 2001.

Recebido em: 23/12/2018 Aprovado em: 09/07/2019

Universidade do Estado de Santa Catarina - UDESC Centro de Ciências Humanas e da Educação - FAED

Revista PerCursos

Volume 20 - Número 43 - Ano 2019 revistapercursos@gmail.com 